\title{
Differences in EFL learners' burnout levels and receptive language skills with regard to the mindfulness- based instruction
}

\author{
Haniyeh Moghadam, ${ }^{1}$ Afsaneh Ghanizadeh ${ }^{1} \&$ \\ Behzad Ghonsooly ${ }^{2}$ \\ ${ }^{1}$ Imam Reza International University Mashhad, Iran \\ ${ }^{2}$ Ferdowsi University of Mashhad, Iran
}

\begin{abstract}
The main aim of education is to provide students with academic knowledge and skills. In this process, some students experience burnout, which negatively affects their productivity and effectiveness. This study experimentally examines the impact of mindfulness-based instruction on burnout and students' achievement in receptive language skills among 64 learners of English as a foreign language (EFL) via a mixed-methods approach (QUAN $\rightarrow$ qual) within a single framework. The techniques implemented in the experimental group, i. e. 32 participants, included observance of all experience, analyzing, planning, judging, reasoning, and fantasizing (van Vreeswijk et al., 2014). Furthermore, the techniques were inspired by Pirson et al. (2012) conceptualization that mindfulness comprises novelty producing, novelty seeking, engagement, and flexibility. The results of posttest revealed these techniques efficiently enhanced the abovementioned variables.
\end{abstract}

Keywords: : EFL learners; mindfulness-based intervention; burnout.

\section{Introduction}

Universal Declaration of Human Rights has formally recognized education as a human right in 1948 (UNICEF, 2007). Education as a guidance empowers humans to know how to face failure, to get success in their life, and to stand on their own feet. A good education makes them acquire new skills, techniques and knowledge so as to provide opportunities for personal, pro- 
fessional, social, and economic development. In today's era, most people across the world are educated by others especially their parents and teachers. This education by a teacher has a profound impact on students' life as they are enabled to analyse circumstances while making decisions for their life, to expand their vision and outlook to see the world.

Burnout, as one of the highly prevalent problems in education, precludes students from achieving their academic objectives. Students experience burnout when they overwork for long periods of time, when they lack control of the situation, and when they have little or no passion for the work or a reason to continue. In recent years, researchers have given considerable attention to the burnout syndrome and their research studies have been conducted in almost every field, and even in non-occupational samples, for example students (Yang, 2004). Previous research demonstrated that students hold the middle to high rank of the burnout scale among nurses, counsellors, and educators. (Malakh-Pines et al., 1981).

At the beginning of the school year, most students start with a lot of enthusiasm, eager to acquire new knowledge and skills, while their materials, and teachers are still new and exciting. As the academic year progresses, they lose their interest due to a load of homework, after-school activities, and tests that they sometimes cannot accomplish in one day. This is why they experience burnout. McCarthy et al. (1990) maintain that the students with burnout feel exhausted because of study demands, have a cynical and detached attitude towards their study, and feel incompetent as a student. According to Maslach (1976), student burnout syndrome manifests in emotional exhaustion, depersonalization, and low personal accomplishment because of the course stress, course load, or other psychological factors. This results in high absenteeism, low motivation to do course work, high percentage dropout, and the like, which are the outcomes of student burnout (Meier \& Schmeck, 1985).

Due to the importance of student burnout (Maslach et al., 2001), teachers should identify the signs of burnout and use effective toolkits to solve this problem and to enhance their teaching. In this study, it is presumed that mindfulness-based techniques can be among the strategies teachers have at their disposal to enhance students' attention, engagement, and interest, and, accordingly, to reduce the risk of burnout. Mindfulness as the other variable considered in the present study comprises four dimensions, including novelty seeking, novelty producing, flexibility and engagement (Pirson et al., 2012). Novelty seeking is the attribute that makes students curious and open toward the environment and themselves. Novelty producing enables students to create novel categories, with innovation and creativity, rather than relying on prior categorizations. Flexibility enables them to consider experiences from different perspectives, which leads to more adaptation to the 
environment. Engagement helps them have the outlook toward an active interaction with the environment, when noticing bigger and subtler details and changes in social/environmental context (Pirson et al., 2012).

By promoting mindfulness in classrooms, teachers can prevent burnout, which affects students' health not just today, but for the rest of their lives and may even be passed on to future generations. The present research aims to address the influence of mindfulness-based instruction on burnout and receptive (reading and writing) language skills achievement among students learning English as a foreign language.

\section{Review of the Related Literature}

\subsection{Mindfulness}

Mindfulness considered as an organizationally relevant social psychological concept (Albert, 1990) has two main approaches. The Eastern approach to mindfulness, closely related to the practice of meditation and westernized by Professor Jon Kabat-Zinn, focuses on present-based attention and a nonevaluative perspective (Kabat-Zinn, 2011). The Western approach to mindfulness which was developed by social psychologist Ellen Langer defines mindfulness as the process of drawing novel distinction. This perspective encompasses three contexts of individuals: external, material, and social (Langer, 1989). Langer (1989) suggested that, in this socio-cognitive approach to mindfulness, a person actively engages in creating novel categories and distinctions due to her/his open mindset towards novelty.

In the social-cognitive approach to mindfulness, novel distinction and appreciation of novelties result in an active mindset in which people are contextually and environmentally sensitive, are in the present moment, notice big and subtle changes, welcome novelties, construct new categories for structuring perception, and have behaviour guided but not governed by rules and routines (Langer \& Moldoveanu, 2000). A mindful individual has an alert state of all mental contents that consists of perceptions, sensations, cognitions, and emotions (Walach et al., 2006) and makes changes in their feelings and their behaviour about a given situation (Langer, 1990). When such individuals pursue this learning agenda that could be very goaloriented, they present multiple perspectives nonjudgmentally resulting in enhancing problem solving and other cognitive exercises (Langer, 1989) and reducing the need for prior established categories, thereby fostering their open mind (Langer, 1992).

Mindfulness enhances attention to, and awareness of experiences taking place in the present moment (Kabat-Zinn, 2013). Awareness refers to an 
ability that makes individual capable of monitoring the inner and outer environment and context constantly, in other words, it is the background radar of consciousness (Brown \& Ryan, 2003). On the other hand, attention refers to an ability that helps individual in the process of having focus of consciousness on her/his limited experience (Brown \& Ryan, 2003). As such, mindfulness can be seen as a state of openness, reception, and nonevaluation of mind (Kabat-Zinn, 1990). Pirson et al. (2012) explicitly stated that attention and awareness underlie engagement, one of the principal subfactors of mindfulness. The higher level of mindfulness, the higher likelihood of flow experiences (Csikszentmihalyi, 1996), and the more meaningful personal engagement will be (Alexander \& Langer, 1990).

The mindful individuals with flexible mindsets present multiple perspectives of distinctions/ categories in the present moment rather than adhering to a single perspective of categories drawn in the past (Langer, 2009). Mindfulness helps to act non-automatically, not to be oblivious to context or perspective (Langer, 2009), to reduce automaticity and habitual actions to what arises in the mind, and to allow for much more responses (Kabat-Zinn, 1990). Mindlessness, by contrast, follows routinized and automatic behaviour that has an effect on the decision-making process since it prevents people from responding with an open mind (Langer, 2009). It could inhibit intuition, creativity, and reception of novel information and perspectives (Langer, 2009). Langer (2009) emphasized that mindfulness is a result of developing the constant repetition of mindsets of categories, associations, and habits of thought during childhood and academic years.

Hayes \& Feldman (2004) reported that mindfulness-based interventions reduce anxiety via raining awareness in the present moment and focusing on favourable intrinsic and extrinsic incentives. To Carbonero (as cited in Franco et al., 2011), anxiety depreciates academic attainment since it is a direct outcome of concentrating attention on negative emotions and perceptions about one's ability to succeed, rather than focusing on the task at hand. Generally, mindfulness-based interventions have been found to have a facilitative role in academic performance and general wellbeing (Hall, 1999).

\subsection{Burnout}

Maslach \& Jackson (1986) presented the most widely used definition of burnout. These authors described burnout as a syndrome of three states of emotional exhaustion, depersonalization, and reduced personal accomplishment. When some researchers such as Freudenberger $(1974,1975)$ and Maslach and her colleagues (Maslach, 1976; Pines \& Maslach, 1978) introduced the burnout construct, burnout has become a popular subject over the years. This popularity led to the development of burnout instruments; for 
example, the MBI (Maslach Burnout Inventory) questionnaire has three subscales: emotional exhaustion, depersonalization, and reduced personal accomplishment. Emotional exhaustion refers to the feeling of depletion or draining of one's emotional resources, considered as the essential individual stress component of the syndrome (Maslach, 1998). Depersonalization, which refers to the development of negative, callous, and cynical outlook towards other people at work, is regarded as the interpersonal component of burnout (Maslach, 1998). Reduced personal accomplishment referring to the tendency to the negative evaluation of one's work and to the decline in one's competence and productivity, represents the self-evaluation component of burnout (Maslach, 1998).

Like Maslach \& Jackson (1986), the study by Pines \& Aronson (1988) suggests that burnout refers to a state of physical, emotional, and mental exhaustion that a person displays when one involves in situations for a long time that are emotionally demanding. Physical exhaustion refers to reduced energy and chronic fatigue, weakness, and various physical and psychosomatic complaints. Emotional exhaustion refers to the feeling of hopelessness, helplessness, and entrapment. Mental exhaustion represents a negative outlook towards an individual's self, work, and life (Pines \& Aronson, 1988). Burnout leads to the tendency to low commitment, absenteeism, reduced productivity, and low morale (Cordes \& Dougherty, 1993).

There are two classifications of burnout: 1) active burnout, which is associated with external variables and 2) passive burnout, which is related to internal variables (Gillespie, 1982). Development of active burnout has been related to the existence of environmental factors and an external locus of control like family members (Meyer, 1982). The existence of internal struggles that are often developed from unresolved personal and/or work issues can contribute to development of passive burnout. Leiter \& Maslach (1988) suggest that development of burnout occurs sequentially in three distinctive phases such as emotional exhaustion, depersonalization, and negative beliefs about personal accomplishments.

Sofield \& Juliano (2000) offered a somewhat different approach presuming that burnout develops in four stages. Individuals in the initial stage are stressful, forgetful, persistently irritable and anxious, and are incapable of concentrating (Girdin et al., 1996). In the second stage of burnout, they have tardiness for work, procrastination, or are late in completing their work assignments (Girdin et al., 1996). The main characteristic of the third stage of burnout is that they suffer from the underlying depression (Sofield \& Juliano, 2000). During the final stage of burnout, the terminal cynicism becomes evident in which they are unable to accept help and assistance from others, especially friends or loved ones, so that they usually need specialized professional help (Sofield \& Juliano, 2000). In educational domain, it has been 
revealed that burnout can affect various dimensions of students' academic performance, including cognitive, emotional, behavioural, and motivational (Ghanizadeh \& Jahedizadeh, 2015). Thus, this study suggests that the impacts of mindfulness-inspired instruction among EFL learners can reduce burnout and enhance language achievement.

\section{Method}

\subsection{Design of the study}

This quasi-experimental research was conducted in a mixed-method approach and the data collection was carried out in two quantitative and qualitative phases. The mix-method approach was used in order to enhance reliability and validity.

In the study, the following research questions were investigated:

1. Does mindfulness-based instruction influence EFL learners' burnout?

2. Does mindfulness-based instruction influence EFL learners' receptive skills (reading and writing)?

\subsection{Participants}

Since there were two phases in data collection, the two sets of participants are described separately as follows.

\subsubsection{Participants of the quantitative phase}

Sixty-four Iranian EFL students participated in this study (47 females and 17 males) with the mean age of 32 years. They had all been studying English at the intermediate levels about six hours a week in a private language institute in Mashhad, a city in the Northeast of Iran. They were divided into four equal groups, i.e., two experimental ones ( 23 females and 9 males) and two control ones (24 females and 8 males). The study included 16 Iranian EFL learners in each of the two experimental groups who were given special, mindfulness-based tasks and 16 Iranian EFL learners in each of the two control groups. The students did a pretest in order to ensure that the students were homogenous in their English proficiency level. Furthermore, in order to ensure participants' homogeneity in burnout level, all participants were asked to respond to the burnout questionnaire prior to the task. 


\subsubsection{Participants of the qualitative phase}

In the second phase, five students of the experimental group were interviewed to see whether and how the innovative mindfulness training influenced their burnout and their language achievement.

\subsection{Instruments}

For collecting data, a language test and the following questionnaire were used in this study.

\subsubsection{The test of the International English Language Testing System (IELTS)}

IELTS is recognized as one of the most reliable and standardized English means of testing people's English language ability for study, work, and travel. It examines four areas of language competence: Listening, Reading, Writing, and Speaking. IELTS scores for each of these four skills are reported on a nine-band scale and moreover, IELTS provides an Overall Band Score from 1 to 9 calculated by averaging these four scores and rounding. There are the same Listening and Speaking tests for all candidates, whereas a candidate chooses Reading and Writing tests based on whether $\mathrm{s} / \mathrm{he}$ is taking the Academic or General Training module. In the present study, two areas of language competence, Listening and Reading were tested. The Listening section lasts approximately 40 minutes and this test has four sections, 10 questions each. The Reading test includes three sections with 40 questions and candidates spend 60 minutes on it. These tests were selected from Tests of Cambridge IELTS 14 General Training: Authentic Practice Tests. The testing procedure does not require specialists to administer it. In order to avoid any subjective view in rating the participants' language competence, so the researchers opted to test Listening and Reading as the students get to choose between the answers that are already offered. Although the other two skills were practiced in this course, due to the problems associated with rating the participants' Speaking and Writing skills, only the scores of the receptive skills were included in the analysis.

\subsubsection{Maslach Burnout Inventory Student-Survey (MBI-SS)}

The researchers utilized the Persian version of Maslach Burnout Inventory Student Survey (MBI-SS) designed and validated by Schaufeli et al. (2002) for assessing EFL student burnout. This scale that has 15 items gauging three dimensions of burnout: (1) emotional exhaustion, (2) cynicism, and (3) academic efficacy. These items are measured on a 7-point Likert-type scale 
connected with the notations ranging from 1 ("always") to 7 ("never") as represented in Table 1 (See Appendix B). In the present study, the Persian version of the scale - translated and validated by Rostami et al. (2014) - was used. The scale revealed acceptable reliability indices ranging from 0.84 to 0.90. In the present study, the reliability of the inventory estimated via Cronbach's alpha was found to be .78 .

Table 1: Items of the Maslach Burnout Inventory-Student Survey

\begin{tabular}{ll}
\hline Factors & Sample Item \\
\hline $\begin{array}{l}\text { Emotional } \\
\text { exhaustion }\end{array}$ & I feel emotionally drained by my studies. \\
\hline Cynicism & $\begin{array}{l}\text { I have become less interested in my studies since } \\
\text { my enrollment at the school. }\end{array}$ \\
\hline Academic Efficacy & $\begin{array}{l}\text { I can effectively solve the problems that arise in my } \\
\text { studies. }\end{array}$ \\
\hline
\end{tabular}

\subsection{Procedure}

In this study, the quantitative and qualitative methods were used.

\subsubsection{Mindfulness-based intervention}

In the first phase, a quasi-experimental design was utilized and conducted in four equal groups. In the first step, to ensure that they were homogenous regarding their proficiency level, participants were asked to answer the Listening and Reading sections of IELTS test. In the second step, for collecting the data, the aforementioned questionnaire, MBI-SS, was distributed among the participants of the four classes after giving the instruction and making the meaning of the items clear for them. Also, they were assured that their responses and views would be kept anonymous and confidential. They cooperated with the researcher voluntarily, answered, and filled them out once at the beginning of the term and then at the end of the term. Furthermore, all of them received a candy and tea in an attempt to ensure a relaxing and cooperative atmosphere between answering the IELTS test and filling the questionnaire. They spent approximately 120 minutes on the IELTS test and the questionnaire. Students spent approximately three months studying English at the intermediate level in the period between July 2019 and September 2019. They six hours / three days a week.

The four classes were taught by the same teacher. Since the main purpose of this study was to investigate the impact of mindfulness-based training on 
learners' burnout and their receptive language skills, this intervention, as a set of classroom techniques, was conducted in the experimental groups and the results were compared with those of the control groups in which mindfulness was not instructed. In this study, the mindfulness-based techniques were drawn from the following principles: the observance of all experience such as perception of senses, thoughts, and feelings, and permission for all experience that includes 1) behaviours, 2) behavioural urges (avoidance behaviour, distraction seeking), and 3) thoughts like analyzing, planning, judging, fantasizing, and reasoning without automatic reaction to it (van Vreeswijk et al., 2014).

In this model, focusing and guiding attention is a precondition. It aims to retain consciousness, which can be displayed in the form of thinking or feeling. What is important here is a stable and sustained attention and the detection of distraction.

The second constituent of the model is developing an approachable and tolerant attitude toward thinking, emotions, and reactions. Segal et al. (2013) called this attitude the doing mode, which automatically arises when an incongruity between our current state and a desired state is detected. In this situation, we try to seek for explanations; concurrently, we attempt to look for solutions for the resultant anxiety. In academic settings, the doing mode includes analyzing, judging, evaluating, solving, assessing, planning, adjusting, and goal setting. The doing mode is more suitable for practical, procedural, and intellectual tasks, although it is commonly used to cope with emotional issues, as well.

When emotions are involved, the being mode- which is somehow the reverse of the doing mode-is used. The being mode is non-judgmental and accepting (Segal et al., 2013). Hence, in the present study, attending to the learners' affective domain and familiarizing them with the detection and management of their emotional state were key strategies in promoting their mindfulness and the resultant academic achievements.

The procedure was inspired by the Pirson et al.'s (2012) operationalization of the four central components of mindfulness: novelty seeking, novelty producing, flexibility and engagement. Overall, the implemented mindfulness-based techniques are displayed in Figure 1. 


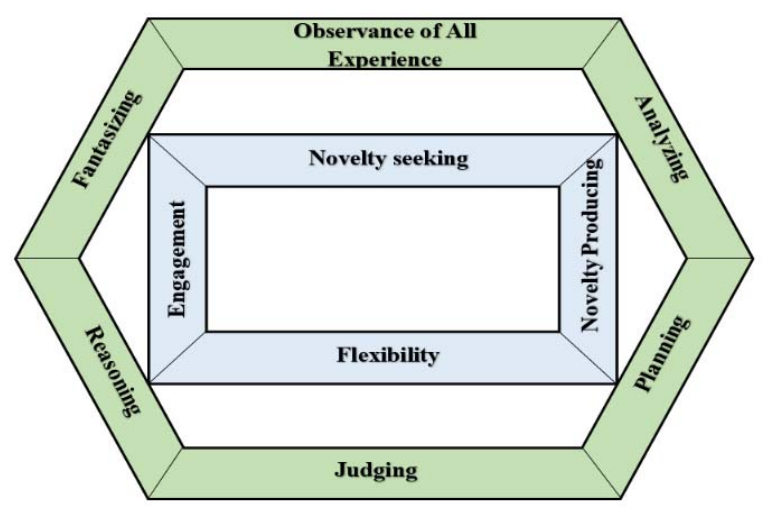

Figure 1: The implemented mindfulness-based techniques, adapted from Vreeswijk et al. (2014: 17).

1) Observance of all experience: Most materials the researchers used were YouTube videos in English. The focus was on one-minute motivational and one-minute daily conversation videos. The main reason why English motivational videos were selected was to help students focus on the present experience and prevent their minds and feelings from wandering in the past or the future. As Lyddy and Good (2017) remarked, mindfulness shifts the state of mind from doing or driven mode to being mode. Via doing mode, mind drifts to the future and past time, whereas in being mode, their mind is retained in the present moment. Furthermore, these English motivational videos offered students positive energy, kept them interested in practicing English and learning the relevant grammar, vocabularies, ideas and so forth so as to understand what these videos were about. Because most of these videos were one-minute motivational ones, they could keep them more concentrated and engaged. On of the examples was a video of a speech by Alexa Rose Carlin (2017) downloaded from YouTube. As they watched the video, their feelings, perceptions, and cognition were keenly involved resulting in creative and novel ideas, positive attitudes, and constructive emotions. As already stated, according to novelty seeking, one of the mindfulness sub-factors, learners are inclined to is to be innovative and receptive toward the context and themselves (Pirson et al., 2012). In the present study, the students were asked to articulate their emotions and ideas whilst watching the video and after watching it. Then they shared their opinions with each other and received feedback from the teacher. Having obtained all these experiences such as perception of senses, thoughts, and feelings through the observance, 
the researchers proceeded with the other techniques, analyzing, planning, judging, reasoning, and fantasizing.

2) Analyzing: in this stage, the students were asked to transcribe the movie, ponder on every sentence of the text, discuss their opinions and interpretation. To facilitate the process, the researchers provided them with the required linguistic, vocabulary, and syntactic knowledge. The students were asked to do the grammar homework from Macmillan English Grammar. This caused learners to be curious, to seek novelty, and to construct new categories and distinctions. This activity is in line with Pirson et al. (2012) contention that in the novelty-producing component of mindfulness, learners tend to generate innovative and creative classifications, with innovation without necessarily relying on prior categories (Pirson et al., 2012).

3) Planning: The third activity required students to watch the movie again, to take notes, and write summaries. They attended to the message as well as individual words, phrases, and sentences. Following that, they generated a concept map or cluster diagram out of their notes. During the process, one of the researchers helped them in identifying the main ideas and establishing connections among ideas. This activity is consistent with the engagement component of mindfulness. It refers to active participation of individuals with themselves, the materials, and the context (Pirson et al., 2012).

4) Judging: At the judging stage, students were required to contemplate on the prior stage and to write an introduction on their own. Then, all students were asked to read their introduction to the classroom while other students discussed it, and finally the most effective introduction was selected by the students. This activity was expected to develop the flexibility component of mindfulness. Flexibility indeed empowers students in seeing the experiences from different angles and equips them to adjust more effectively to the context (Pirson et al., 2012).

5) Reasoning: At this stage, students were encouraged to write the body and conclusion of their writings through generating a concept map or cluster diagram. They were specifically asked to ponder on their conclusion while one of the researchers monitored and scaffolded the activity. The body and conclusions were read in the class while the others commented on them. Through this phase, the novelty producing aspect was expected to flourish.

6) Fantasizing: All these activities were reiterated for daily conversational movies. Furthermore, students were asked to visualize each movie and then do a role play at the fantasizing stage. They were asked to practice their role plays and to write about different aspects of the topic of films. For example, for the movie transcribed earlier in this paper, they reflected about their dreams, wrote about them, created the concept map, and acted it in the class. 
The researchers used the Longman Communication 3000 as the other material. It is a list of the 3000 most frequent vocabulary items in spoken and written English. About 10 minutes out of the 90 minute-class time were devoted to teach some of these vocabulary items with some details involving meaning, pronunciation, part of speech, and collocations. Students wrote the new story in their groups at a Telegram app to receive feedback from the teacher and their classmates, and told their story in the next session in the class. In order to stimulate motivation in learning English, students were allowed to send new and favorite motivational movies to their groups and shared their emotions and feedbacks with others after watching.

Meanwhile, the control group received their listening activities by means of audio-tapes and some discussion questions. Then, the researchers taught grammar, vocabulary, collocation, colligation, and formal and informal structures, that the participants in the control group were required to know. They were asked to do the homework assigned from Macmillan English Grammar in Context. Also, they listened again to make some notes individually to write the summary after the teacher instructed them how to draw a semantic mapping or clustering, categorize their information based on presentation, reason and consequence, and write the case example or inline example. Finally, they wrote and spoke in the class based on what they had listened to. Moreover, although the same vocabulary entries of the Longman Communication 3000 were taught in the experimental and control groups taking about 10 minutes out of the 90 minute- class time with some details involving meaning, pronunciation, part of speech, and some collocations, students did not write a new story based on these vocabulary units as the participants in the experimental group did. Indeed, the participants in the control group practiced some routine and mainstream activities with no exploration and discovery learning involved. In addition, no specific attempt was made to activate their concentration and engage their full attention by focusing on the present experience and impeding their minds and feelings from wandering in the past or the future.

\subsubsection{Interview}

In the second phase, in order to capture the quality of the mindfulness-based techniques as classroom activities and explore students' attitudes and reactions towards these techniques in the two experimental classes, the qualitative part was carried out by interviewing five participants of the experimental groups who were chosen randomly. They were asked to articulate about their experiences, and to explain whether mindfulnessbased techniques had any impact on their attitudes and perceptions, and how it facilitated their learning process. The interviews were recorded and analyzed accordingly. 


\subsection{Data Analysis}

To carry out this mixed methods study and to analyze the data in this study, the researchers took advantage of the software packages below:

SPSS (Statistical Package for the Social Sciences): After the responses collected from the questionnaires were tabulated, this software was employed for analyzing and validating the data. To compare the performance of the two groups in the variables under study, independent samples $t$-test was employed.

MAXQDA 18: This software has been designed for computer-assisted qualitative and mixed methods data, text, and multimedia analysis in academic, scientific, and business institutions developed and distributed by VERBI Software based in Berlin, Germany. This was utilized for both coding and categorizing the data from interviews. In addition, the access was given to provide different models for antecedents and consequences separately.

\section{Results}

\subsection{The results of the quantitative phase}

\subsubsection{The results of the pretest}

To examine the existence of any significant difference between control and experimental groups on their language proficiency level (in receptive skills), an independent samples $t$-test was used. Table 2 shows the descriptive results of proficiency test assessed via IELTS in the two groups. As the table indicates, the mean scores of proficiency in the two groups do not differ greatly: control $(M=9.91, S D=.82)$, experimental $(M=9.94, S D=.80)$.

Table 2: Descriptive statistics of proficiency across control and experimental groups

\begin{tabular}{llllcc}
\hline & Groups & $\mathrm{N}$ & Mean & Std. Deviation & Std. Error Mean \\
\hline Pre- & Control & 32 & 9.91 & .82 & .14 \\
\cline { 2 - 6 } IELTS & Experimental & 32 & 9.94 & .8 & .14 \\
\hline
\end{tabular}

To ascertain whether this observed difference is statistically nonsignificant, the results of $t$-test should be examined. As can be seen, there is not a statistically significant difference between the two groups regarding their proficiency level of receptive language skills $(t=-.15, p=.87)$. In other words, the two groups are homogenous regarding their level of language proficiency level prior to conducting the study. 
Table 3: Independent sapples t-test showing the results of pretest on proficiency level

\begin{tabular}{|c|c|c|c|c|c|c|c|}
\hline & \multicolumn{4}{|c|}{$\begin{array}{l}\text { Levene's Test } \\
\text { for Equality of } \\
\text { Variances }\end{array}$} & \multirow{2}{*}{\multicolumn{2}{|c|}{$\begin{array}{l}\text { Sig. (2-Mean } \\
\text { tailed) Differenc }\end{array}$}} & \\
\hline & $\mathrm{F}$ & Sig. & $\mathrm{t}$ & $\mathrm{df}$ & & & $\begin{array}{l}\text { Std. Error } \\
\text { eDifference }\end{array}$ \\
\hline $\begin{array}{l}\text { Pre- } \\
\text { IELTS }\end{array}$ & .09 & .75 & -.15 & 62 & .87 & -.03 & .20 \\
\hline
\end{tabular}

Identical analysis was carried out for burnout. Table 4 displays the descriptive statistics of burnout in the pre-test. As the table reveals, the mean scores of burnout in the two groups are slightly different: control $(M=32.38$, $S D=7.41)$, experimental $(M=31.13, S D=7.01)$.

Table 4: Descriptive statistics of burnout across control and experimental groups

\begin{tabular}{llllllc}
\hline & & & & & Std. & Error \\
& Groups & $\mathrm{N}$ & Mean & Std. Deviation Mean & \\
\hline Pre- & Control & 32 & 32.38 & 7.42 & 1.31 \\
\cline { 2 - 7 } Burnout & Experimental & 32 & 31.13 & 7.01 & 1.24 & \\
\hline
\end{tabular}

To ensure whether this slight difference is statistically non-significant, an independent samples $t$-test was run. Table 5 presents the results of $t$-test run on burnout. As can be seen, no statistically significant difference was observed between the two groups regarding their level of burnout $(t=.69$, $p=.49)$.

Table 5: Independent samples t-test showing the results of pretest on burnout

\begin{tabular}{|c|c|c|c|c|c|c|c|}
\hline & \multicolumn{7}{|c|}{$\begin{array}{l}\text { Levene's Test } \\
\text { for Equality } \\
\text { of Variances }\end{array}$} \\
\hline & $\mathrm{F}$ & Sig. & $t$ & $\mathrm{df}$ & $\begin{array}{l}\text { Sig. } \\
(2- \\
\text { tailed) }\end{array}$ & $\begin{array}{l}\text { Mean } \\
\text { Difference }\end{array}$ & $\begin{array}{l}\text { Std. Error } \\
\text { eDifference }\end{array}$ \\
\hline $\begin{array}{l}\text { Pre_ } \\
\text { Burnout }\end{array}$ & .28 & .59 & .69 & 62 & .49 & 1.25 & 1.80 \\
\hline
\end{tabular}




\subsubsection{The results of the posttest}

To inspect the impact of mindfulness-based instruction on students' language achievement (receptive skills), an independent samples $t$-test was run. Table 6 presents the mean scores of receptive language skills across participants in control and experimental groups a: control $(M=10.31$, $S D=.47)$, experimental $(M=12.47, S D=1.13)$.

Table 6: Descriptive statistics of language achievement across control and experimental groups

\begin{tabular}{lllllll}
\hline & & & & & Std. & Error \\
& Groups & $\mathrm{N}$ & Mean & Std. Deviation Mean & \\
\hline Post- & Control & 32 & 10.31 & .74 & .13 & \\
\cline { 2 - 6 } IELTS & Experimental 32 & 12.47 & 1.13 & .20 & \\
\hline
\end{tabular}

These findings are also presented visually in the following bar graph (Figure 2). As the figure shows, the mean score of IELTS in experimental group is higher than that of the control group.

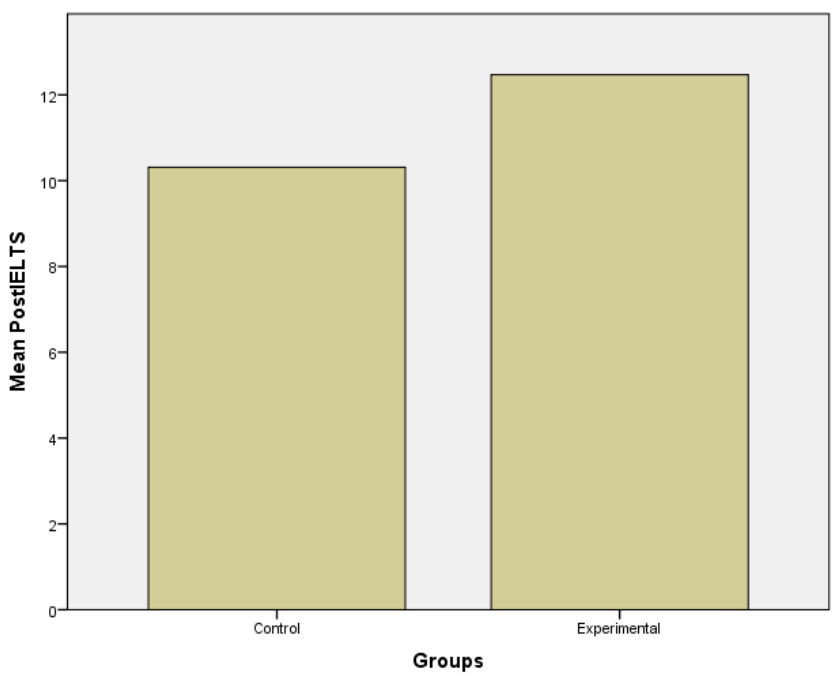

Figure 2: The mean scores of the IELTS across the two groups.

To see whether this observed difference is statistically significant, we should refer to the results of independent samples $t$-test. As can be seen in Table 7 , there is a statistically significant difference between the two groups regarding the level of their receptive skills proficiency $(t=-9.00, p=.00)$. The 
effect size calculated via Cohen's $d$ was found to be -2.26 which is a high magnitude according to Cohen's $d$ index. In other words, the two groups are significantly different regarding their level of reading and writing achievement. This is an indication of the efficiency of the treatment employed in the experimental group.

Table 7: Independent samples t-test showing the results of posttest on language achievement

\begin{tabular}{|c|c|c|c|c|c|c|}
\hline & $\begin{array}{l}\text { Leve } \\
\text { Test } \\
\text { Equ } \\
\text { of } \mathrm{V} \\
\text { ance }\end{array}$ & $\begin{array}{l}\text { ne's } \\
\text { for } \\
\text { lity } \\
\text { ari- } \\
\text { s }\end{array}$ & & & & \\
\hline & F & Sig. & $\mathrm{df}$ & $\begin{array}{l}\text { Sig. } \\
(2- \\
\text { tailed) }\end{array}$ & $\begin{array}{l}\text { Mean } \\
\text { Difference }\end{array}$ & $\begin{array}{l}\text { Std. Error } \\
\text { eDifference }\end{array}$ \\
\hline $\begin{array}{l}\text { Post } \\
\text { IELTS }\end{array}$ & 8.88 & .00 & -9.0062 & .00 & -2.15 & .24 \\
\hline
\end{tabular}

To explore the role of mindfulness in burnout, another analysis was run. Table 8 exhibits the descriptive statistics of burnout in control and experimental groups after the treatment. As can be seen, the mean score of burnout is lower in experimental group in comparison with that of the control group: control $(M=36.56, S D=9.83)$, experimental $(M=22.06$, $S D=3.48)$.

Table 8: Descriptive statistics of burnout across control and experimental groups

Std. Error

\begin{tabular}{llllll} 
& Groups & $\mathrm{N}$ & Mean & \multicolumn{2}{c}{ Std. Deviation Mean } \\
\hline Post- & Control & 32 & 36.56 & 9.83 & 1.74 \\
\cline { 2 - 6 } Burnout & Experimental & 32 & 22.06 & 3.48 & .62 \\
\hline
\end{tabular}

To have a more vivid picture of the above finding, the bar graph of the mean scores of burnout of control and experimental groups in post-test was generated. Figure 3 illustrates the bar graph. As can be seen, students in experimental group displayed lower level of burnout. 


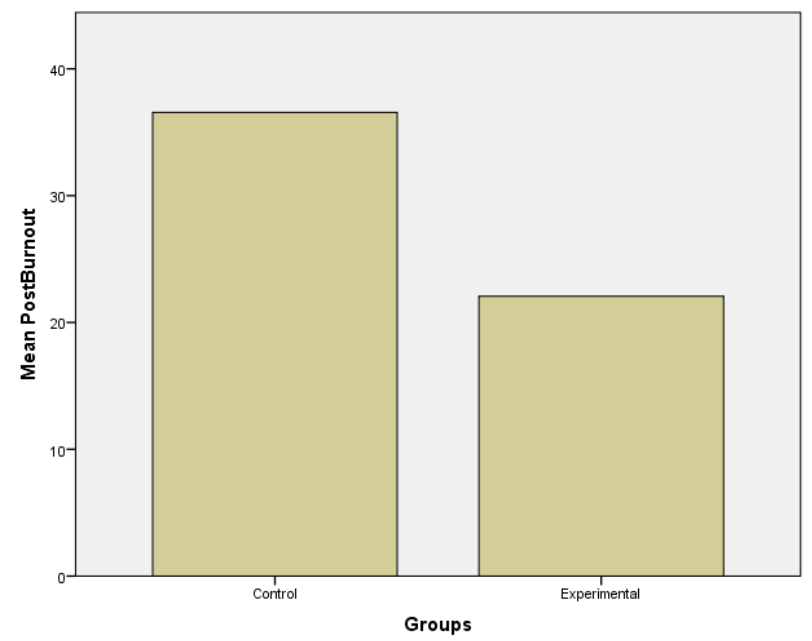

Figure 3: The mean scores of burnout across the two groups.

To examine the significance of this difference, we should consider Table 9. As can be seen, there is a statistically significant difference between the two groups regarding the level of their burnout $(t=7.86, p=.00)$. The effect size calculated via Cohen's $d$ was found to be 1.97 which is a moderate magnitude according to Cohen's $d$ index. It implies the efficiency of mindfulness-based technique in reducing burnout.

Table 9: Independent samples t-test showing the results of posttest on burnout

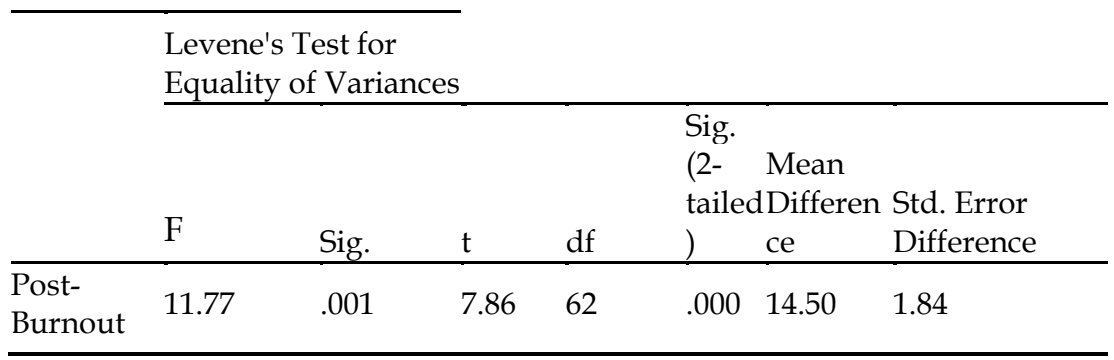

\subsection{The results of the qualitative phase}

The data of the effects of mindfulness-based teaching were coded by the researchers according to the information gathered by the interviews. All data were carefully studied and classified into three basic categories of 1) 
mindfulness role in emotional exhaustion, 2) mindfulness role in cynicism, and 3) mindfulness role in academic inefficacy, each of which is classified into different subcategories.

The result of the first category is presented in Figure 4 that is created by MAXQDA 18 software and demonstrates all the effects that come into play as the results of mindfulness-based instruction (all the data supported the positive effect of mindfulness on reducing students' levels of burnout).

As the figure shows, this type of instruction had great impact on the first dimension of burnout. The codes and parent codes are depicted in Figure 4.

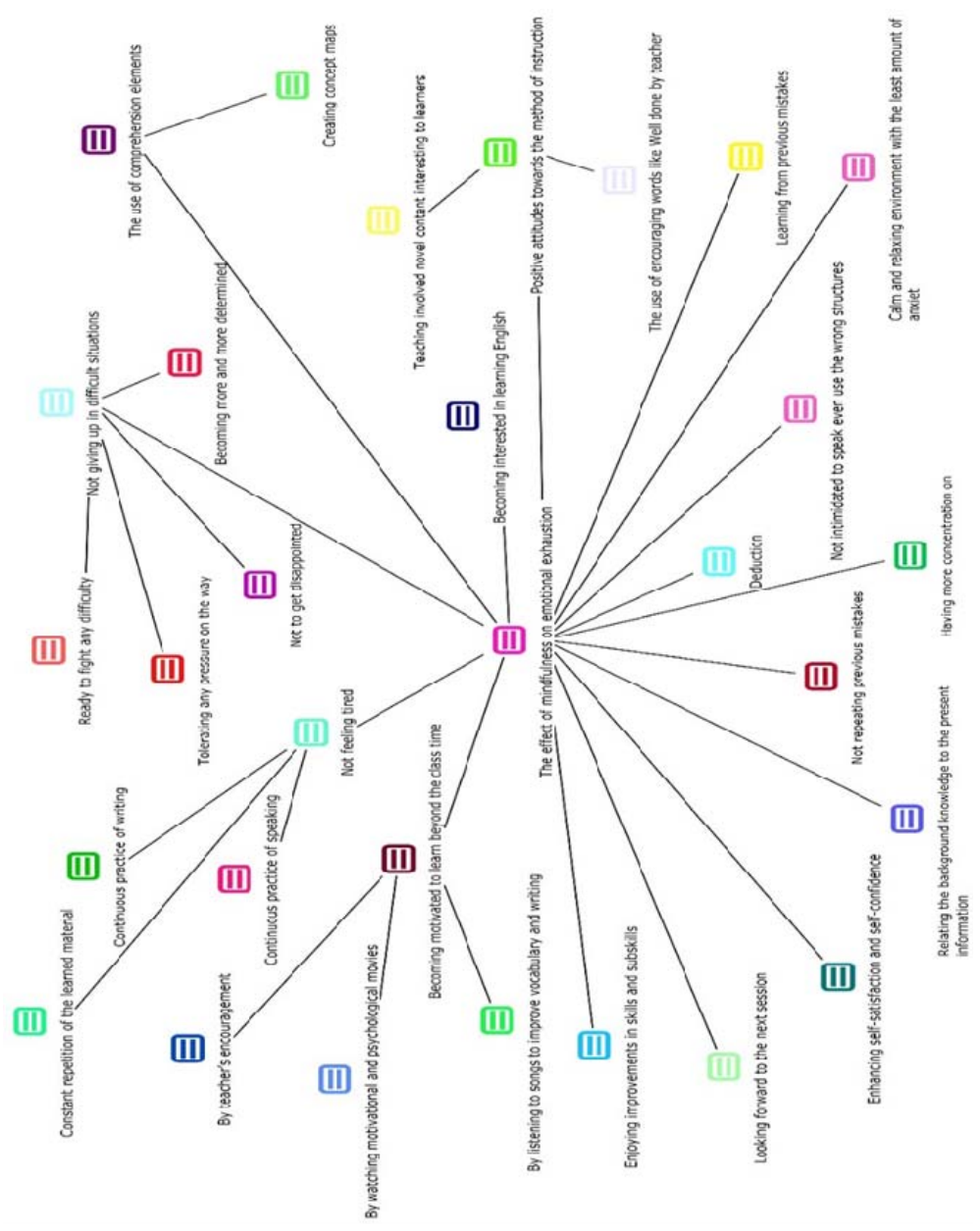

Figure 4: The model of the effects of mindfulness-based instruction on emotional exhaustion 


\begin{tabular}{|c|c|c|c|c|}
\hline \multicolumn{5}{|c|}{ 염 图 } \\
\hline 1 & Code-ID & Position & Parent code & Code \\
\hline - & 135 & 40 & The effect of mindfuliness on burnout the effect of mirdffiness on enoticna exhaustion & Becoming interested in learning Erglish \\
\hline$\square$ & 136 & 34 & The effect of mindffiness on burnout The effect of mirdffiness on emoticna exhaustion & Not feeling tred \\
\hline 1. & 137 & 39 & The effect of nindfiliness on burnout the effect of mirdffilness on emotional exhaustion Wlot feeling tired & Constant repettion of the learned material \\
\hline ( & 138 & 36 & The effect of mindfulness on burnout the effect of mindfulness on enctiona exhaustion Wot feeling tired & Continuous prastice of speaking \\
\hline - & 139 & 38 & The effect of mindfuliness on burnout The effect of mirdffuness on enotiona exhaustion Wot feeling tired|Continuous practi... & By recording the voice \\
\hline - & 140 & 37 & The effect of mindfuliness on burnout the effect of mirdffiliness on enotional exhuustion Wot feeling tired Continuous practi... & Of both accuracy and fuency \\
\hline - & 141 & 35 & The effect of minffuiness on burnout the effect of mirdffilness on enotiona exhaustion|Wot feeling tired & Continuous practice of wrting \\
\hline - & 142 & 30 & The effect of mindffilness on burnoutthe effect of mindfuliness on enoticna exhaustion & Becoming motivated to learn beyond the dass time \\
\hline - & 143 & 33 & The effect of mindfulness on burnout The effect of mindffiness on enotional exhaustion Beconing motivated to learn beyo... & By teacher's encouragement \\
\hline प & 144 & 32 & The effect of mindffiness on burnout the effect of mirdffilness on enoticnal exhoustion Beconing motivated to learn beyo... & By watthing motivational and psychological movies \\
\hline - & 145 & 31 & The effect of mindfuliness on burnout the effect of mirdffinness on enoticna exhaustion Beconing motivated to learn beyo... & By listenirg to sorgs to improve vocablary and witing \\
\hline -1. & 146 & 29 & The effect of nindfulness on burnout the effect of mindffilness on enotiona exhaustion & Enjoying inprovements in skils and subskils \\
\hline in & 147 & 28 & The effect of mindfulness on burnout the effect of mindfulness on enotiona exhrustion & Looking forvard to the next session \\
\hline - & 148 & 27 & The effect of mindfuliness on burnout the effect of mirdfuliness on enotiona exhaustion & Enhanong self-sabisfaction and sef-corffidence \\
\hline 【 & 149 & 26 & The effect of mindffiness on burnoutthe effect of mirdffilness on enotiona exhaustion & Not repeating previous mistckes \\
\hline 7 & 1.50 & 21 & The effect of mindffuness on burnoutt|the effect of mirdffulness on enotiona exhaustion & Not giving up in difficults siluations \\
\hline - & 151 & 25 & The effect of mindffilness on burnoutt The effect of mirdfulness on enotiona exhaustion Wot giving up in diffcut situations & Ready to fight any dfficulty \\
\hline - & 152 & 24 & 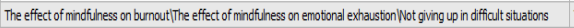 & Toleratng any pressure on the way \\
\hline 【 & 153 & 23 & The effect of mindffulness on burnoutt The effect of mirdfulness on enctional exhaustion Wot giving up in diffcut situations & Becoming more ard more determined \\
\hline 【 & 1.54 & 22 & The effect of nindfulness on burnout The effect of nindfulness on enotiona exhaustion Wot giving up i diffcut situations & Not to get disappointed \\
\hline - & 155 & 20 & The effect of mindffulness on burnoutțhe effect of mindffilness on enotiona exhaustion & Relating the background hnowledge to the presentinformation \\
\hline I & 156 & 17 & The effect of nindffiness on burnout the effect of nirdffilness on enctiona exhaustion & Having more concentration on \\
\hline it & 159 & 16 & 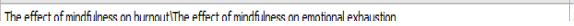 & nepdurtion \\
\hline
\end{tabular}

Figure 5: The codes and subcodes of the mindfulness-based instruction role in emotional exhaustion

Figure 5 displays all codes that can be regarded as the most significant effects of mindfulness on emotional exhaustion. These codes are ordered in the following list:

1. Becoming interested in learning English

2. Not feeling tired

2.1. Constant repetition of the learned material

2.2. Continuous practice of speaking

2.2.1. By recording the voice

2.2.2. Of both accuracy and fluency

2.3. Continuous practice of writing

3. Becoming motivated to learn beyond the class time

3.1. By teacher's encouragement

3.2. By watching motivational and psychological movies

3.3. By listening to songs to improve vocabulary and writing

4. Enjoying improvements in skills and subskills

5. Looking forward to the next session

6. Enhancing self-satisfaction and self-confidence

7. Not repeating previous mistakes

8. Not giving up in difficult situations

8.1. Ready to fight any difficulty

8.2. Tolerating any pressure on the way

8.3. Becoming more and more determined

8.4. Not to get disappointed

9. Relating the background knowledge to the present information 
10. Having more concentration on

10.1. What is done

10.2. Concentrating on each word that is expressed

11. Calm and relaxing environment with the least amount of anxiety/stress

12. Learning from previous mistakes

13. Positive attitudes towards the method of instruction

13.1. Teaching involved novel content interesting to learners

13.2. The use of encouraging words like Well done by teacher

14. The use of comprehension elements

14.1.1. Categorizing

14.1.2. Revising

14.1.3. Reviewing

14.1.4. Note taking

14.1.5. Summarizing

14.1.6. Creating concept maps

15. Not intimidated to speak even use the wrong structures

16. Deduction

Figure 6 shows the model of the effect of mindfulness-based instruction on students' cynicism.

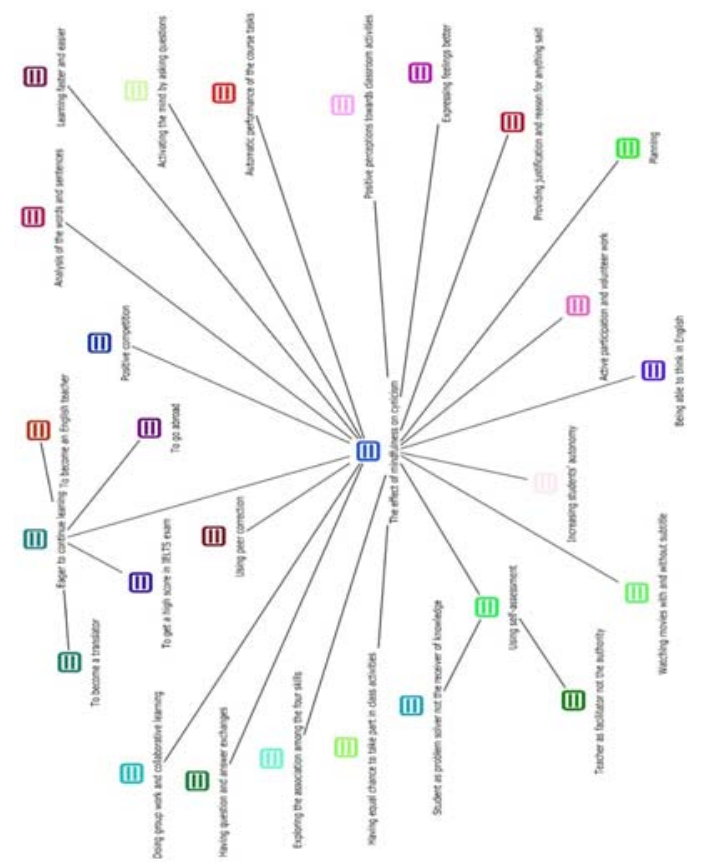

Figure 6: The model of the effects of mindfulness-based instruction on cynicism 
As the figure shows, this type of instruction had great impact on EFL students' cynicism. The codes and parent codes are depicted in Figure 7.

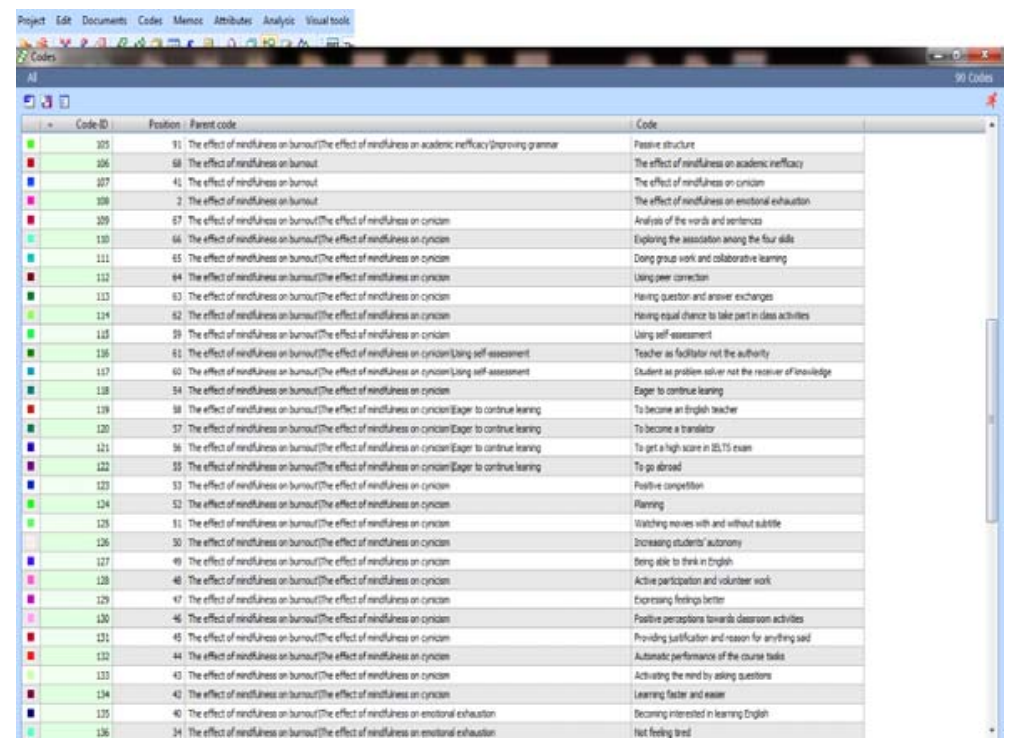

Figure 7. The codes and sub codes of the mindfulness-based instruction role in cynicism

Figure 7 reveals all codes that can be regarded as the most significant effects of mindfulness on cynicism. These codes are ordered in the following list:

1. Analysis of the words and sentences

2. Exploring the association among the four skills

3. Doing group work and collaborative learning

4. Using peer correction

5. Having question and answer exchanges

6. Having equal chance to take part in class activities

7. Using self-assessment

7.1.1. Teacher as facilitator not the authority

7.1.2. Student as problem solver not the receiver of knowledge

8. Eager to continue leaning

8.1. To become an English teacher

8.2. To become a translator

8.3. To get a high score in IELTS exam

8.4. To go abroad

9. Positive competition 
10. Planning

11. Watching movies with and without subtitle

12. Increasing students' autonomy

13. Being able to think in English

14. Active participation and volunteer work

15. Expressing feelings better

16. Positive perceptions towards classroom activities

17. Providing justification and reason for anything said

18. Automatic performance of the course tasks

19. Activating the mind by asking questions

The last part focused on the effect of mindfulness-based instruction on students' academic inefficacy. Figure 8 demonstrates all the effects that came into play as the result of mindfulness-based instruction.

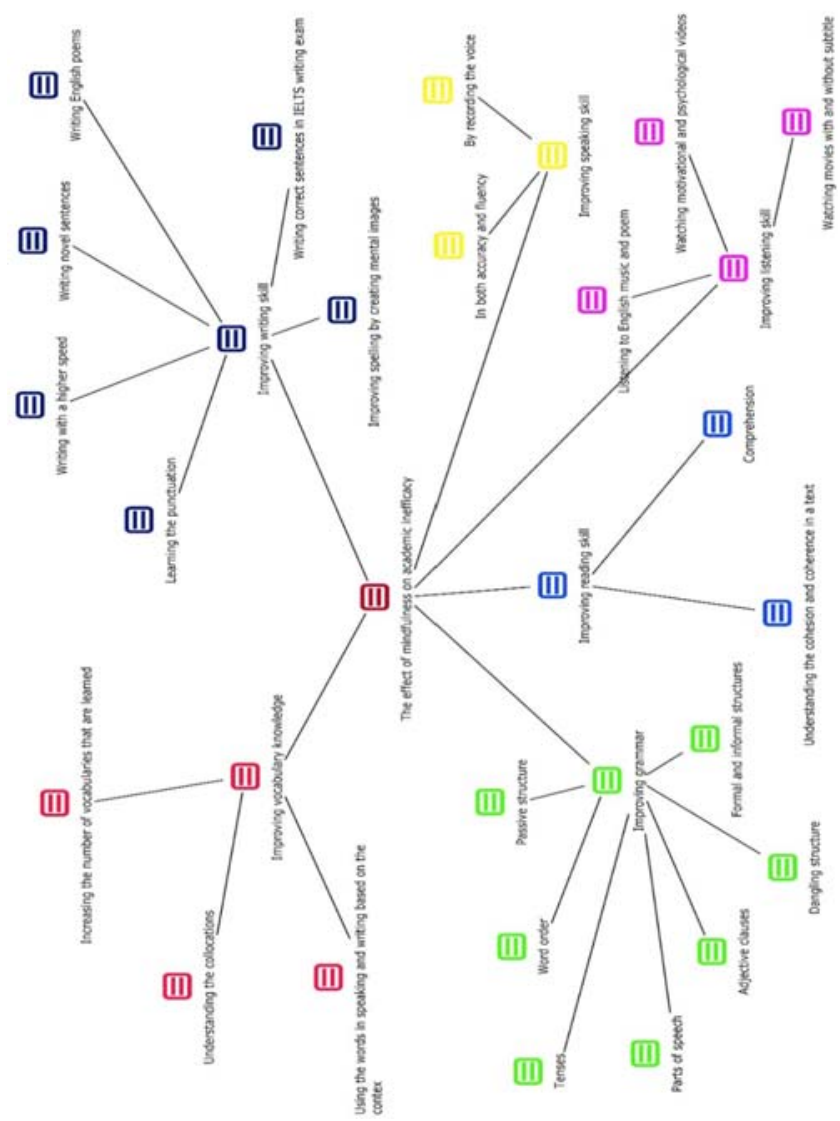

Figure 8: The model of the effects of mindfulness-based instruction on academic inefficacy 
Haniyeh Moghadam, Afsaneh Ghanizadeh \& Behzad Ghonsooly: Differences in EFL learners' burnout levels and receptive language skills with regard to the mindfulness-based instruction

\begin{tabular}{|c|c|c|c|c|}
\hline \multicolumn{2}{|c|}{ P Codes } & 1 & 10 & 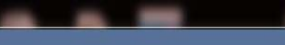 \\
\hline \multicolumn{5}{|c|}{$x=-4=-20$} \\
\hline \multicolumn{5}{|c|}{ 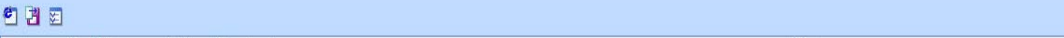 } \\
\hline 1 & Code-ID & Postion & Parent code & Code \\
\hline - & 76 & 1 & 1 & The effect of mindfuness on burnout \\
\hline - & 77 & 69 & 9 The effect of mindffiness on burnouttThe effect of mindfilress on academicinefficacy & Inproving witing skil \\
\hline - & 78 & 75 & 5 The effect of mindfilness on burnouttithe effect of minduless on accodemis inefficacy Improving writing skil & Writing correct sentences in IETTS writing exam \\
\hline - & 79 & 74 & 4 The effect of mindfilness on burnoutt, The effect of mindfliress on academic inefficacy Improving writing skil & Writhg novel sentences \\
\hline 【 & 80 & 73 & 3 The effect of mindfiliness on burnout The effect of mindfulress on academic inefficacy|Improving writing skil & Writing English poems \\
\hline - & 81 & 72 & 2 The effect of mindfuluess on burnout the effect of mindfulress on academic inefficacy|Improving writing skil & Improving spelling by creating mental images \\
\hline 【 & 82 & 71 & 1 The effect of nindfuluess on burnout The effect of mindfulress on academis inefficacy IImproving writing skil & Learning tre punctuation \\
\hline - & 83 & 70 & The effect of mindfiluess on burnout the effect of mindfulress on academis inefficacy Improving writing skil & Writing with a higher speed \\
\hline II & 84 & 76 & 5 The effect of mindfiliness on burnout, The effect of mindiluress on accademic inefficacy & Improving spesking skill \\
\hline III & 85 & 78 & 8 The effect of mindfiliness on burnout The effect of mindfilress on academicineffitacy Improving speaking skill & By recording the voice \\
\hline 17 & 86 & 77 & 7 The effect of mindfulness on burnout The effect of mindfilress on academic inefficacy Improving speaking skill & In bothaccuracy and fuency \\
\hline - & 87 & 79 & The effect of mindfulness on burnouttThe effect of mindfilness on academic inefficacy & Improving Istenirg skill \\
\hline - & 86 & 82 & 2 The effect of minffulness on burnout The effect of mindfulress on academic inefficacy Improving istening sill & Listering to English musc and poem \\
\hline 1 & 89 & 81 & 1 The effect of mindfilness on burnout The effect of mindfilress on academic inefficacy Improving istening sill & Watthing moves with and without subtitle \\
\hline - & 90 & 80 & The effect of mindfilness on burnout The effect of mindfiress on academic inefficacy /mproving istering sall & Watching mottuatornal and psychological videcs \\
\hline - & 91 & 83 & 3 The effect of mindfulness on burnout The effect of mindfiress on academic inefficacy & Improving reading skill \\
\hline - & 92 & 85 & 5 The effect of mindfulness on burnout The effect of mindfulress on academic inefficacy Improving reading sill & Comprehension \\
\hline ॥ & 93 & 84 & 4 The effert of mindfuliness on burnout The effect of mindfulress on academicinefficacy Improving reading skill & Understanding the cohesion and coherence in a text \\
\hline 【 & 94 & 86 & 5 The effert of mindfinness on burnouttThe effect of mindiliress on accdenicinefficacy & Inproving vocabulary knowledge \\
\hline - & 95 & 89 & 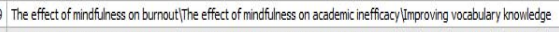 & Increasing the number of vocabuaries that are learred \\
\hline - & 96 & 88 & 8 The effect of mindfulness on burnout The effect of mindfulress on academic inefficacy Improving vocabulary knowledge & Using the words in speaking and writing based on the contex \\
\hline - & 97 & 87 & 7 The effect of mindfulness on burnout The effect of mindfulress on academic inefficacylImproving vocabulary knowledge & Understanding the collocations \\
\hline 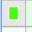 & 98 & 90 & The effert of nindfulness on burnout The effect of mindfulress on academis inefficasy & Improving granmar \\
\hline - & 99 & 97 & 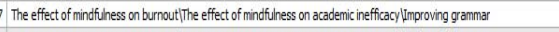 & Formal and informal stucuctures \\
\hline ע & 100 & 96 & 5 The effect of mindfulness on burnout, The effect of mindfilress on academic inefficacy/Improving grammar & Dangling stucture \\
\hline I & 101 & 95 & 5 The effect of mindfulness on burnout The effect of mindfilress on academic inefficacy IImproving granmar & Adjective dauses \\
\hline I & 102 & 94 & 4 The effect of mindfulness on burnout The effect of mindfulress on academic inefficacylimproving granmar & Parts of speech \\
\hline 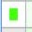 & 103 & 93 & 3 The effert of mindfulness on burnout The effect of mindfilress on academici inefficasyl Improving grammar & Tenses \\
\hline - & 104 & 92 & 2 The effert of mindfulness on burnout The effect of mindfulress on academis inefficacy Improving granmar & Word order \\
\hline 1 & 105 & 91 & 1 The effect of mindfulness on burnout The effect of mindfilress on academic inefficacy Improving grammar & Passive structure \\
\hline
\end{tabular}

Figure 9: The codes and sub codes of the mindfulness-based instruction role in academic inefficacy

As the figure illustrates, this type of instruction had great impact on EFL students' academic inefficacy. The codes and parent codes are depicted in Figure 9.

Figure 9 revealed all codes that can be regarded as the most significant effects of mindfulness on academic inefficacy. These codes are ordered in the following list:

1. Improving writing skill

1.1. Writing correct sentences in IELTS writing exam

1.2. Writing novel sentences

1.3. Writing English poems

1.4. Improving spelling by creating mental images

1.5. Punctuation

1.6. Writing with a higher speed

2. Improving speaking skill

2.1. By recording my voice

2.2. In both accuracy and fluency

3. Improving listening skill 
3.1. Via listening to English music and poem

3.2. Watching movies with and without subtitle

3.3. Watching motivational and psychological videos

4. Improving reading skill

4.1. Comprehension

4.2. Understanding the cohesion and coherence in a text

5. Improving vocabulary knowledge

5.1. Increasing the number of vocabularies that are learned

5.2. Using the words in speaking and writing based on the context

5.3. Understanding the collocations

6. Improving grammar

6.1. Formal and informal structures

6.2. Dangling

6.3. Adjective clauses

6.4. Enhancement of the knowledge of parts of speech

6.5. Tenses

6.6. Word order

6.7. Passive structure

6.8. Learning faster and easier

\section{Discussion}

According to Vreeswijk et al. (2014), mindfulness training equips people for success in life to become fully-functioning persons of the society and, furthermore, upon the above-mentioned definition of Pirson et al. (2012), four key sub-factors of mindfulness are novelty seeking, novelty producing, flexibility and engagement. Inspired by these contentions and definitions, in the present study, the researchers conjectured that mindfulness-based intervention would have positive impacts on burnout depletion and language achievement.

To investigate the hypotheses of this study, this study utilized a quasiexperimental design among 64 EFL learners. The results of posttest showed that there was a significant difference in control and experimental groups regarding the level of their burnout under the influence of mindfulnessbased techniques. In other words, the efficiency of mindfulness-based technique utilized in the experimental groups resulted in burnout depletion. The results of qualitative phase were also in line with the findings of the quantitative phase. The above finding corroborates previous research. For example, some interventions such as the Cultivating Awareness and Resilience in Education (CARE) program and the Stress Management and Relaxation Techniques (SMART)-in-Education program indicated that the regulation of concentration and awareness could reduce burnout (Jennings et al., 2011; 
Roeser et al., 2013) as a three-dimensional syndrome that consists of three dimensions: emotional exhaustion, cynicism, and academic inefficacy (Schaufeli et al., 2002).

In particular, the results of this study revealed that using mindfulnessbased intervention in experimental groups positively resulted in the enhancement of receptive skills. As to the influence of mindfulness-based intervention on academic achievement, several studies have reported results similar to those of this study (Hall, 1999). Hall (1999) noted that there is a growing body of scientific evidence that mindfulness-based interventions might have a major positive impact on some factors which are relevant to academic performance and general wellbeing (Hall, 1999). He also noted that these enhancements include: 1) attention, focus and concentration, 2) cognitive processing, 3) working memory and perception, and 4) emotional and social intelligence that includes emotion regulation and social, altruistic, or pro-social behaviour (Hall, 1999). Hence mindfulness makes a positive impact on students' educational performance and academic attainment by enriching attention and awareness (Baena-Extremera et al., 2021; Schoeberlein \& Sheth, 2009).

The above findings are also in line with the studies reported in the field of L2 education, although these studies are quite sparse in number and extent. Takiguchi (2015) maintained that mindfulness can be an effective approach in enhancing L2 learners' language learning and promoting educators' socio-emotional competence. He proposed four one-day sessions over four to five weeks, via online or live courses. The courses include guided instructions in in mindfulness mediation practices, mindful yoga, and group discussions in English. It was found that these programs not only English proficiency, but also increased natural capacity to respond more effectively to stress and burnout while enhancing awareness in everyday life and daily assignments in practicing English. In another study, Moafian et al. (2017) in an attempt to validate the Persian version of MBI-SS substantiated significant positive relationship between the Persian MBI-SS and positive affect, physical health, psychological health and environmental health among EFL learners.

In a recent book on cultivating higher order thinking skills (HOTS) in language classes, Ghanizadeh et al. (2020) introduced several techniques. One of the techniques revolves around regulation of attention and selfawareness, i.e., mindfulness-intervention procedure. It is undeniable when thinking skills are enhanced, learning, including language learning, will facilitate.

The qualitative phase demonstrated this effect through participants' verbal explanations concerning the positive role of mindfulness in their language success. For example, learners articulated that their writing skill was 
improved to a large extent, in that they could create correct sentences in IELTS writing exam, novel sentences, and English poems with a higher speed and correct punctuation. This is in line with Saurel's (2017) study explaining that mindfulness improves writing through affecting the brain's neural patterns in a positive way, improving social relationships, and controlling stress (Saurel, 2017). Besides, it was revealed that mindfulness can improve students' listening and speaking skills through listening to English music and poem, watching movies with and without subtitle, and watching motivational and psychological videos. This is in harmony with Cammarata's (2016) contention that mindfulness plays a key role in enhancing communicative skills via paying attention to details.

Reading skill (comprehension, cohesion, and coherence), vocabulary knowledge and grammar (collocations, formal and informal structures, dangling structure, adjective clauses, parts of speech, tenses, word order, and passive structure) were also found to be the among the positive effects of mindfulness-based instruction (e.g., Clawson, 2019; Maynard et al., 2017).

Mindfulness helps individuals sustain their attention in the present rather than in the past and in the future (Kabat-Zinn, 1994) and fosters openness and acceptance so that their direct experience are not clouded by their preconceptions (Kabat-Zinn, 1990). This means that it increases their ability to deviate from automatic negative thinking, develops their cognitions, and promotes their cognitive flexibility (Frewen et al., 2008) to lead to broaden their perspectives (Langer, 1990). Deakin-Crick et al. (2015) stated that mindful agency exhibits a positive association with innovation, emotional attachment, and engagement. Hence, it can be said that such optimism and positive outlook replaces cynicism as one of "negative" dimensions of burnout. One line of justification for this finding could be based on the Langer's (1990) contention stating that mindful people avoid habitual actions, habitual negative thoughts, emotions and behavioural patterns.

Similarly, Ying (2008) showed that mindfulness minimizes the effect of one of "negative" dimensions (i.e. exhaustion), which is relevant to experiences in an academic settings among students. Since if individuals are emotionally exhausted, they feel emotionally worn-out and drained as a result of exposure to particular working conditions or stressors for a long period of time (Bakker et al., 2004) and of accumulated stress from their lives. According to Schaufeli et al. (2002), students experiencing emotional exhaustion feel burned out from their studies and feel like they could not control what happens in their lives meaning they feel like they got stuck. Therefore, the novelty seeking sub-construct of mindfulness helps them pay attention to what's going on around them (Langer, 2009), and be curious and open toward the environment and themselves (Pirson et al., 2012), leading to reducing stress, stimulating creativity, and boosting performance instead of operating on 
autopilot (Langer, 2009) and then it alleviates or prevents symptoms of emotional exhaustion (Baena-Extremera et al., 2021).

When mindfulness promotes awareness and acceptance, it disengages an individual from their automatic pilot, and allows for new ways to respond (Langer, 1990). In effect, its novelty producing sub-construct enables individuals create novel categories, with innovation and creativity, rather than relying on prior categorizations (Pirson et al., 2012). In addition, the flexibility sub-construct is the one which enables individuals to consider experiences from different perspectives and which results is better adaptation to the environment (Pirson et al., 2012). It is interesting to mention that the engagement sub-construct is the one which has the outlook toward an active interaction with the environment, when noticing bigger and subtler details and changes in social/environmental context (Pirson et al., 2012). Therefore, it implies that the mindful students with positive outlook are capable of concentrating on learning more attentively and enthusiastically in the class.

Overall, this study sought to decrease the EFL students' burnout with the use of mindfulness treatment. Based on the statistical results, the experimental groups experienced less burnout in comparison with the control groups. In other words, becoming interested in learning English, expressing feelings better, becoming motivated to learn beyond the class time, positive perceptions towards classroom activities, positive classroom environment and competition, positive method of instruction, positive attitudes towards speaking, self-satisfaction, positive self-concept, enhancing self-confidence and courage, not feeling tired and burnout, being eager to continue learning, and positive vision of the future position were among the effects of mindfulness on emotional exhaustion, cynicism, and academic inefficacy.

\section{Pedagogical implications}

The findings of the present study have important implications for teachers, educational policy-makers, and materials developers. They must acknowledge the idea that mindfulness training acts as a buffer for teachers that have great concerns about how they should teach in their classes. As such, educationalists and policy makers should adopt mindfulness-based interventions (MBIs) as a part of educational programming and inject mindfulness in the classroom so that students are equipped with abilities conducive to success during their academic endeavors and in their lives to become fully-functioning persons of the society. Moreover, materials developers can design textbooks and tasks based on mindfulness-based instruction to enhance students' burnout and help them learn in an appropriate classroom environment. 


\section{Conclusions}

Taken together, the present study demonstrated the efficiency of mindfulness-based instruction in promoting various aspects of EFL learners' learning, including cognitive, metacognitive, and motivational dimensions. Indeed, mindfulness helps reduce stress levels and positively affects individuals' meta-cognition, executive functioning, focus and attention, academic achievement, social skills, range of knowledge in regards to emotions, emotion regulation skills, and self-efficacy resulting in standing up to unfavorable situations and scenarios (Albrecht, 2014; Burke, 2010; Carelse, 2013; Coholic, 2011). In the current study, it can be seen that one-minute motivational movies not only relieved students' stress and burnout, and provided positive energy, but also could empower students with positive and promising stance, and higher levels of creativity and originality in their writing and speaking. Such students are more likely to achieve a positive view on themselves, their English learning, their academic performance, and their engagement in learning, as they hope to continue studying English in the future in order to achieve a higher grade in an IELTS exam. Indeed, they see their academic achievement in the course based on the differences of scores at the beginning and at the end of the term. All in all, it can safely be concluded that mindfulness-based intervention has the potential to influence all aspects of learning, including cognitive, metacognitive, motivational, and emotional dimensions.

The present quasi-experimental study intended to explore the effect of mindfulness-based instruction on EFL students' burnout and language achievement in Mashhad, Iran, based on questionnaires and interviews. The study also offers some recommendations for future research. This study can be replicated in different ways. First, it can use a larger sample so that some other factors may be discovered and it can benefit from more generalizability. Second, it can be carried out in other cities in Iran or in other countries. Third, there is a need to replicate the study in the context of public schools creating the opportunity to compare and contrast the results with each other. It is also worthwhile to conduct a study on the effect of this type of instruction on other pertinent constructs.

\section{References}

Albert, Stuart (1990). Mindfulness, an important concept for organizations: A book review essay on the work of Ellen Langer. Academy of Management Review 15: 154-159. 
Albrecht, Nicole J. (2014). Wellness: A conceptual framework for school-based mindfulness programs. The International Journal of Health, Wellness, and Society 4: 21-36.

Alexander, Charles N., Ellen J. Langer (1990). Higher Stages of Human Development: Perspectives on Adult Growth. New York: Oxford University Press.

Bakker, Arnold B., Evangelia Demerouti, Willem Verbeke (2004). Using the job demands-resources model to predict burnout and performance. Human Resource Management 43(1): 83-104.

Baena-Extremera, Antonio, María del Mar Ortiz-Camacho, Alba M. Marfil-Sánchez, Antonio Granero-Gallegos (2021). Improvement of attention and stress levels in students through a mindfulness intervention program. Revista de Psicodidáctica 26(2): 132-142. https:// doi.org/10.1016/j.psicoe.2020.12.002

Brown, Kirk Warren, Richard M. Ryan (2003). The benefits of being present: Mindfulness and its role in psychological well-being. Journal of Personality and Social Psychology 84 (4): 822-848.

Burke, Christine A. (2010). Mindfulness-based approaches with children and adolescents: A preliminary review of current research in an emergent field. Journal of Child and Family Studies 19: 133-144.

Cammarata, Larry (2016). This mindfulness practice will improve your communication. Retrieved 4 May, 2019 fromm https://www.massagemag.com/this-mindfulness-practice-will-improve-your-communication- 40658

Carlin, Alexa Rose (2017). The World Needs More Of You/ 1 Minute Motivational Speech. Retrieved 14 June, 2019 from https://www.youtube.com/channel/ UCZNYh4wbRfKmfB9k8gKXUwQ

Carelse, Bernadette (2013). Children's Experiences of Learning Mindfulness to Help Develop their Attentional Skills (Doctoral thesis). University of East London, United Kingdom.

Clawson, Adam Joseph (2019). Understanding the Relation between Mindfulness-Based Interventions, Reading and Attention. (MA Thesis). Syracuse University.

Coholic, Diana A. (2011). Exploring the feasibility and benefits of arts-based mindfulness-based practices with young people in need: Aiming to improve aspects of self-awareness and resilience. Child Youth Care Forum 40: 303-317.

Cordes, Cynthia L., Thomas W. Dougherty (1993). A review and integration of resource on job burnout. Academy of Management Review 18: 621-656.

Csikszentmihalyi, Mihaly (1996). Finding Flow: The Psychology of Engagement with Everyday Life. New York: Basic Books.

Deakin-Crick, Ruth, Shaofu Huang, Adeela Ahmed Shafi, Chris Goldspink (2015). Developing resilient agency in learning: The internal structure of learning power. British Journal of Educational Studies 63: 121-160.

Freudenberger, Herbert J. (1974). Staff burnout. Journal of social issues 30: 159-165.

Freudenberger, Herbert J. (1975). The staff burnout syndrome in alternative institutions. Psychotherapy: Theory, Research and Practice 12: 72-83.

Frewen, Paul A., Elspeth M. Evans, Nicholas Maraj, David J. A. Dozois, Kate Partridge (2008). Letting go: Mindfulness and negative automatic thinking. Cognitive Therapy and Research 32: 758-774.

Franco, Clemente, Israel Mañas, Adolfo J. Cangas, José Gallego (2011). Exploring the effects of a mindfulness program for students of secondary school. International Journal of Knowledge Society Research 2: 14-28. 
Ghanizadeh, Afsaneh, Ali Al-Hoorieh, Jahedzadeh Safoura (2020). Higher Order Thinking Skills in the Language Classroom: A Concise Guide. Cham: Springer.

Ghanizadeh, Afsaneh, Jahedzadeh Safoura (2015). Teacher burnout: A review of sources and ramifications. British Journal of Education, Society $\mathcal{E}$ Behavioural Science 6(1): 23-39.

Gillespie, David F. (1982). Correlates for active and passive types of burnout. Journal of Social Science Research 4: 1-16.

Girdin, Daniel A., George S. Everly, Dorothy E. Dusek (1996). Controlling Stress and Tension. Needham Heights, MA: Allyn \& Bacon.

Hall, Pamela D. (1999). The effect of meditation on the academic performance of African American college students. Journal of Black Studies 29: 408-415.

Hayes, Adele M., Greg Feldman (2004). Clarifying the construct of mindfulness in the context of emotion regulation and the process of change in therapy. Clinical Psychology: Science and Practice 11: 255-262.

Jennings, Patricia A., Karin E. Snowberg, Micheal A. Coccia, Mark T. Greenberg (2011). Improving classroom learning environments by Cultivating Awareness and Resilience in Education (CARE): Results of two pilot studies. Journal of Classroom Interaction 46: 37-48.

Kabat-Zinn, Jon (1990). Full Catastrophe Living: Using the Wisdom of your Body and Mind to Face Stress, Pain and Illness. New York: Delacourt.

Kabat-Zinn, Jon (1994). Wherever You Go, There You Are: Mindfulness Meditation in Everyday Life. New York: Hyperion.

Kabat-Zinn, Jon (2011). Some reflections on the origins of MBSR, skillful means, and the trouble with maps. Contemporary Buddhism 12: 281-306.

Kabat-Zinn, Jon (2013). Full Catastrophe Living: Using the Wisdom of your Body and Mind to Face Stress, Pain and Illness. New York: Bantam Dell.

Langer, Ellen J. (1989). Mindfulness. Cambridge, MA: De Capon Press.

Langer, Ellen J. (1990). Mindfulness. American Health 9: 54-54.

Langer, Ellen J. (1992). Matters of mind: mindfulness/mindlessness in perspective. Consciousness and Cognition 1: 289-305.

Langer, Ellen J. (2009). Counter Clockwise: Mindful Health and the Power of Possibility. New York, NY: Ballantine Books.

Langer, Ellen J., Moldoveanu Mihnea (2000). The construct of mindfulness. Journal of Social Issues 56: 1-9.

Leiter, Micheal P., Christina Maslach (1988). The impact of interpersonal environment on burnout and organizational commitment. Journal of Organizational Behaviour 9: 297-308.

Lyddy, Christopher J., Darren J. Good (2017). Being While Doing: An Inductive Model of Mindfulness at Work. Frontiers in Psychology, Retrieved 6 May, 2019. https://doi.org/10.3389/fpsyg.2016.02060

Malakh-Pines, Ayala, Elliot Aronson, Ditsa Kafry (1981). Burnout: From Tedium to Personal Growth. New York: Free Press.

Malakh-Pines, Ayala, Elliot Aronson (1988). Career Burnout: Causes and Cures. New York: Free Press.

Maslach, Christina (1976). Burn-out. Human Behaviour 5: 16-22.

Maslach, Christina (1998). A multidimensional theory of burnout. In C. L. Cooper (Ed.), Theories of organizational stress. Oxford: Oxford University Press, 68-85. 
Maslach, Christina, Susan E. Jackson (1986). MBI: Maslach Burnout Inventory; Manual Research Edition. Palo Alto, CA: University of California, Consulting Psychologists Press,

Maslach, Christina, Wilmar B. Schaufeli, Micheal P. Leiter (2001). Job burnout. Annual Review of Psychology 52: 397-422.

Maynard, Brandy R., Michael R. Solis, Veronica L. Miller, Kristen E. Brendel (2017). Mindfulness-based interventions for improving cognition, academic achievement, behavior, and socioemotional functioning of primary and secondary school students. Campbell Systematic Review 2017: 13(1): 1-144.

McCarthy, Mary E., Grace M. Pretty, Victor Catano (1990). Psychological sense of community and student burnout. Journal of College Student Development 31: 211-216.

Meier, Scott T., Ronald R. Schmeck (1985). The burned-out college student: A descriptive profile. Journal of College Student Personal 26: 63-69.

Meyer, John H. (1982). Burnout: Developmental influences. Canadian Counselor 16: 67-73.

Moafian, Fatemeh, Francesco Pagnini, Hooshang Khoshsima (2017). Validation of the Persian version of the Langer mindfulness scale. Frontiers in Psychology 8: 468.

Pines, Ayala, Christina Maslach (1978). Combatting staff burnout in a day care setting: a case study. Child Quarterly 9: 5-16.

Pirson, Micheal, Ellen J. Langer, Todd Bodner, Sigal Zilcha-Mano (2012). The development and validation of the Langer mindfulness scale-enabling a sociocognitive perspective of mindfulness in organizational contexts. Retrieved 26 March, 2019 from http:/ / ssrn.com/abstract=2158921

Roeser, Robert W., Kimberly A. Schonert-Reichl, Amishi Jha, Margaret Cullen, Linda Wallace, Rona Wilensky, Eva Oberle, Kimberly Thomson, Cynthia Taylor, Jessica Harrison (2013). Mindfulness training and reductions in teacher stress and burnout: Results from two randomized, waitlist-control field trials. Journal of Educational Psychology 105: 787-804.

Rostami, Zeinab, Mohammad Reza Abedi, Wilmar B. Schaufeli (2012). Dose interest predicts academic burnout? Interdisciplinary Journal of Contemporary Research in Business 3: 877-885.

Saurel, Susan (2017). How mindfulness makes you a better writer. Retrieved 6 October, 2019 from https://www.livewritethrive.com/2017/06/22/howmindfulness-makes-you-a-better-writer/.

Schaufeli, Wilmar B., Isabel A. Martinez, Alexandra M. Pinto, Marisa Salanova, Arnold B. Bakker (2002). A measurement of engagement and burnout: A two sample confirmatory factor analytic approach. Journal of Happiness Studies 3: 71-92.

Segal, Zindel V., J. Mark G. Williams, John D. Teasdale (2013). Mindfulness-based Cognitive Therapy for Depression (2nd edn.). New York: Guilford Publications.

Schoeberlein, Deborah D., Suki Sheth (2009). Mindful Teaching and Teaching Mindfulness: A Guide for Anyone Who Teaches Anything. Boston: Wisdom Publications.

Sofield, Loughlan, Carroll Juliano (2000). Collaboration: Uniting Our Gifts in Ministry. Notre Dame, IN: Ave Maria Press. 
Takiguchi, Harumi. (2015). Implementing mindfulness into teaching English as a second language at the colleague level: An exploratory study. Departmental Bulletin Paper 50: 127-142.

UNICEF/UNESCO. (2007). A Human Rights-based Approach to Education for All. New York: UNICEF Publications.

van Vreeswijk, Michiel, Jenny Broersen, Ger Schurink (2014). Mindfulness and Schema Therapy: A Practical Guide. Malden: Wiley-Blackwell.

Walach, Harlad, Nina Buchheld, Valentin Buttenmuller, Norman Kleinknecht, Stefan Schmidt (2006). Measuring mindfulness-the freiburg mindfulness inventory (FMI). Personality and Individual Differences 40: 1543-1555.

Yang, Hui-Jen (2004). Factors affecting student burnout and academic achievement in multiple enrolment programs in Taiwan's technical-vocational colleges. International Journal of Educational Development 24: 283-301.

Ying, Yu-Wen (2008). The buffering effect of psychological detachment against emotional exhaustion among social work students. Journal of Religion and Spirituality in Social Work: Social Thought 27: 131-150.

\title{
Authors' addresses
}

Hanieh Moghadam

Daneshgah Ave, English Department, Imam Reza International University, Mashhad, Iran

P.O. box: 9138833186

e-mail h.moghadam62@gmail.com

\author{
Afsaneh Ghanizadeh \\ Daneshgah Ave, English Department, Imam Reza International University, \\ Mashhad, Iran \\ P.O. box: 9138833186 \\ e-mail: afsanehghanizadeh@gmail.com; a.ghanizadeh@imamreza.ac.ir \\ Behzad Ghonsooly \\ Park Square, English Department, Ferdowsi University of Mashhad, Iran \\ e-mail: ghonsooly@um.ac.ir
}

Received: September 10, 2020

Accepted for publication: January 6, 2021 


\section{Appendices}

Appendix A. Items of the Langer Mindfulness Scale (LMS)

\begin{tabular}{|c|c|c|c|c|c|c|c|c|}
\hline \multicolumn{2}{|r|}{$\begin{array}{l}\text { Questionnaire } 1 \\
\text { Directions: This questionnaire is designed to help } \\
\text { us gain a better understanding of your views } \\
\text { concerning teaching. Your answers are confidential. } \\
\text { Please circle your respond to the items. }\end{array}$} & 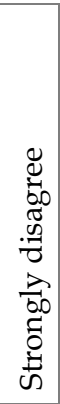 & 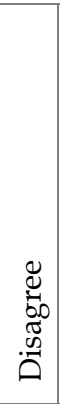 & 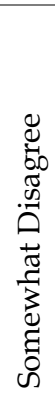 & 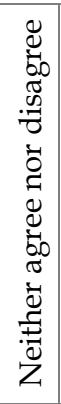 & 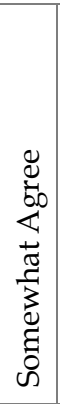 & $\underset{\circlearrowright}{\circlearrowright}$ & \multirow[t]{2}{*}{ 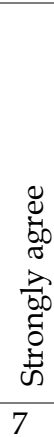 } \\
\hline 1 & I like to investigate things. & 1 & 2 & 3 & 4 & 5 & 6 & \\
\hline 2 & I generate few novel ideas. & 1 & 2 & 3 & 4 & 5 & 6 & 7 \\
\hline 3 & I make many novel contributions. & 1 & 2 & 3 & 4 & 5 & 6 & 7 \\
\hline 4 & I seldom notice what other people are up to. & 1 & 2 & 3 & 4 & 5 & 6 & 7 \\
\hline 5 & I avoid thought provoking conversations. & 1 & 2 & 3 & 4 & 5 & 6 & 7 \\
\hline 6 & I am very creative. & 1 & 2 & 3 & 4 & 5 & 6 & 7 \\
\hline 7 & I am very curious. & 1 & 2 & 3 & 4 & 5 & 6 & 7 \\
\hline 8 & I try to think of new ways of doing things. & 1 & 2 & 3 & 4 & 5 & 6 & 7 \\
\hline 9 & I am rarely aware of changes. & 1 & 2 & 3 & 4 & 5 & 6 & 7 \\
\hline 10 & I like to be challenged intellectually. & 1 & 2 & 3 & 4 & 5 & 6 & 7 \\
\hline 11 & $\begin{array}{l}\text { I find it easy to create new and effective } \\
\text { ideas. }\end{array}$ & 1 & 2 & 3 & 4 & 5 & 6 & 7 \\
\hline 12 & I am rarely alert to new developments. & 1 & 2 & 3 & 4 & 5 & 6 & 7 \\
\hline 13 & I like to figure out how things work. & 1 & 2 & 3 & 4 & 5 & 6 & 7 \\
\hline 14 & I am not an original thinker. & 1 & 2 & 3 & 4 & 5 & 6 & 7 \\
\hline
\end{tabular}




\section{Appendix B. Maslach-student burnout inventory}

\begin{tabular}{|c|c|c|c|c|c|c|}
\hline \multicolumn{2}{|r|}{$\begin{array}{l}\text { Questionnaire } 2 \\
\text { Directions: This questionnaire is designed to help us } \\
\text { gain a better understanding of your views concerning } \\
\text { teaching. Your answers are confidential. } \\
\text { Please circle your respond to the items. }\end{array}$} & \multirow{2}{*}{ 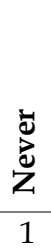 } & \multirow{2}{*}{$\begin{array}{l}\text { ह } \\
\frac{0}{0} \\
\text { ஸे } \\
2\end{array}$} & \multirow{2}{*}{ 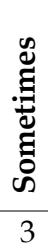 } & \multirow{2}{*}{$\underset{4}{\stackrel{ \pm}{ \pm ~}}$} & \multirow{2}{*}{$\frac{\substack{\text { D } \\
\frac{3}{4}}}{5}$} \\
\hline 1 & I feel emotionally drained by my studies. & & & & & \\
\hline 2 & $\begin{array}{l}\text { I have become less interested in my studies since } \\
\text { my enrollment at the school. }\end{array}$ & 1 & 2 & 3 & 4 & 5 \\
\hline 3 & $\begin{array}{l}\text { I can effectively solve the problems that arise in } \\
\text { my studies. }\end{array}$ & 1 & 2 & 3 & 4 & 5 \\
\hline 4 & I feel used up at the end of a day at school. & 1 & 2 & 3 & 4 & 5 \\
\hline 5 & $\begin{array}{l}\text { I have become less enthusiastic about my } \\
\text { studies. }\end{array}$ & 1 & 2 & 3 & 4 & 5 \\
\hline 6 & $\begin{array}{l}\text { I believe that I make an effective contribution to } \\
\text { the classes that I attend. }\end{array}$ & 1 & 2 & 3 & 4 & 5 \\
\hline 7 & I feel burned out from my studies. & 1 & 2 & 3 & 4 & 5 \\
\hline 8 & In my opinion, I am a good student. & 1 & 2 & 3 & 4 & 5 \\
\hline 9 & $\begin{array}{l}\text { I have learned many interesting things during } \\
\text { the course of my studies. }\end{array}$ & 1 & 2 & 3 & 4 & 5 \\
\hline 10 & $\begin{array}{l}\text { I feel tired when I get up in the morning and I } \\
\text { have to face another day at school. }\end{array}$ & 1 & 2 & 3 & 4 & 5 \\
\hline 11 & $\begin{array}{l}\text { I have become more cynical about the potential } \\
\text { usefulness of my studies. }\end{array}$ & 1 & 2 & 3 & 4 & 5 \\
\hline 12 & I feel stimulated when I achieve my study goals. & 1 & 2 & 3 & 4 & 5 \\
\hline 13 & $\begin{array}{l}\text { Studying or attending a class is really a strain for } \\
\text { me. }\end{array}$ & 1 & 2 & 3 & 4 & 5 \\
\hline 14 & I doubt the significance of my studies. & 1 & 2 & 3 & 4 & 5 \\
\hline 15 & $\begin{array}{l}\text { During class I feel confident that I am effective } \\
\text { in getting things done. }\end{array}$ & 1 & 2 & 3 & 4 & 5 \\
\hline
\end{tabular}




\section{List of Abbreviations}

CARE: Cultivating Awareness and Resilience in Education

EFL: English as Foreign Language

IELTS: International English Language Testing System

LMS: Langer Mindfulness Scale

MBIs: Mindfulness-based interventions

MBI-SS: Maslach Burnout Inventory Student-Survey

SPSS: Statistical Package for the Social Sciences

SMART: Stress Management and Relaxation Techniques

UNICEF: United Nations International Child 